\title{
Fabric Thickness Measurement under Tensile Forces
}

\author{
Diana Šimić Penava ${ }^{1, *}$, Željko Penava ${ }^{2}$ and Željko Knezić ${ }^{2}$ \\ ' Faculty of Civil Engineering, University of Zagreb, Department of Engineering Mechanics, Zagreb, Croatia \\ 2 Faculty of Textile Technology, University of Zagreb, Department of Textile Design and Management, Zagreb, Croatia
}

\begin{abstract}
Woven fabric thickness (t) is its third dimension, which is considerably smaller than the fabric width and length, but at the same time it is very important because it affects the usage and properties of the fabric. During stretching, the fabric thickness is changing depending on the value of the tensile force. In an effort to be as precisely as possible to measure dynamic thickness changes of the fabric, and simultaneously collect all the required values about the change of the tensile force, extension and the area on which tensile force acts, new measuring apparatus are designed and manufactured. This measuring apparatus allows the simultaneous measurement of dynamic thickness of fabric, the fabric contraction and related tensile axial forces.
\end{abstract}

Keywords: thickness; woven fabrics; tensile force; extension.

\section{Introduction}

Under fabric thickness the greatest distance between the surface of the front side and the mutually parallel surface of the back side of the fabric is meant. Fabric thickness is measured in $\mathrm{mm}$. Fabric thickness plays an important role in manual processing, design and end-use of textiles. Fabric thickness change, depending on the effect of various parameters [1]. In order to clarify the effects of some specific parameters on fabric thickness, such as yarn count change, change of warp and weft density, change of warp and weft thread tension in the weaving process, it is necessary to carry out experimental tests of fabric thickness change. To allow a real understanding of thickness behavior when a fabric is stretched, it has been necessary to develop a precise new device for measuring fabric thickness. A textile fabric is a very flexible material and it is easy to imagine that, during such a test, the sample moves a lot in the three spatial directions. Moreover, a textile fabric is made of interlaced yarns constituted of fibers twisted together [2]. Various apparatuses for measuring static thickness have been developed. Haven used a new fabric thickness-measurer [3], Shiefer used a compressometer for thickness and resilience measurements [4]. The non-contacting measurements [5, 6] (optical) were too heavy to be fixed on the fabric without deforming it. It came out that the fabric should carry the sensor during the test.

The aim of this work was to measure the dynamic change of fabric thickness using a newly constructed device when the fabric was in the axial state of stress in the weft and warp direction.

\section{Hydraulic hammer measurement}

The experimental part deals with measurements of fabric thickness if tensile force acts on fabric samples until rupture. For this purpose a new device for dynamic measurements of fabric thickness changes, if tensile force acts on the fabric sample, was designed and constructed. The values of tensile forces, associated extensions 
and associated fabric thicknesses were found during testing.

Two cotton woven fabrics of different weft density and of the same warp density were available. In this work, only balanced orthogonal plain weave fabric was considered. Cotton yarn for the warp and weft had the same yarn count. Table 1 shows structural properties of the tested woven fabrics.

Tab. 1: Description of fabrics.

\begin{tabular}{|c|c|c|c|c|c|c|}
\hline \multirow{2}{*}{$\begin{array}{l}\text { Fabric } \\
\text { code }\end{array}$} & \multicolumn{2}{|c|}{$\begin{array}{l}\text { Yarn count } \\
\text { (tex) }\end{array}$} & \multicolumn{2}{|c|}{$\begin{array}{l}\text { Number of } \\
\text { yarns }\left(\mathrm{cm}^{-1}\right)\end{array}$} & \multirow{2}{*}{$\begin{array}{l}\text { Mass } \\
\left(\mathrm{g} / \mathrm{m}^{2}\right)\end{array}$} & \multirow{2}{*}{$\begin{array}{l}\text { Thickness } \\
\text { to }(\mathrm{mm})\end{array}$} \\
\hline & warp & weft & warp & weft & & \\
\hline F1 & 30 & 30 & 24 & 19 & 137 & 0.365 \\
\hline F2 & 30 & 30 & 24 & 27 & 168 & 0.371 \\
\hline
\end{tabular}

The yarn count was determined by the gravimetric method according to standard ISO 2060:1994. The number of threads per unit length was tested according to standard ISO 7211-2:1984.

Fig. 1: Schematic representation of the device for measuring fabric thickness during extension.
Initial woven fabric thickness to is measured on newly-constructed apparatus at a pressure of $2 \mathrm{cN} / \mathrm{cm}^{2}$. Before testing all specimens were conditioned under the conditions of standard atmosphere (relative air humidity $65 \pm 2 \%$, at a temperature of $20 \pm 2^{\circ} \mathrm{C}$ ).

For the purposes of this testing, standard samples with dimensions $300 \times 50 \mathrm{~mm}$ were cut and clamped in the clamps of the tensile tester at a distance of $l_{0}=200 \mathrm{~mm}$ and subjected to uniaxial tensile load till rupture. The pulling speed of the clamps was $100 \mathrm{~mm} / \mathrm{min}$. The samples were cut in the weft direction and in the warp direction. Five tests were carried out on the new designed device for the mentioned cutting directions of the specimen. For each cutting direction, the average values of axial force, associated extension and thickness, obtained from five measurements are shown in diagrams.

Using new constructed apparatus, a fabric test specimen is stretched and loaded at a constant pulling speed until the moment of specimen rupture. Figure 1 shows the schematic representation of the apparatus for measuring fabric thickness.

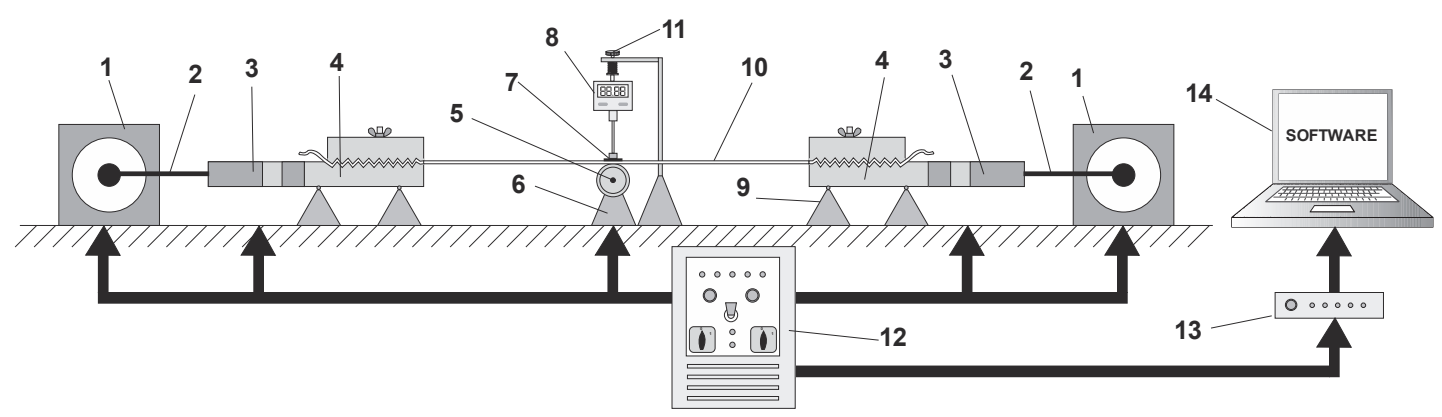

The constructed device is fully automated, computer-controlled and works at a constant pulling speed. Maximum measuring resolution of pulling (stretching) is $3.5 \mu \mathrm{m}$. The test specimen of fabric (10) is fastened between the movable fabric clamps. The clamps are moved by the electric drive (1) using the transmission system (2) at a constant speed, and they move by means of the screw rod (4) fastened to the bearing structure (1). The force transducer cell (3) is connected to the clamp on the one side, and on the other side the motor (1) moves the clamp by the transmission system (2). A force transducer cell for a range to $200 \mathrm{~N}$ is used. The electric motor work ( 1 ) is computer-controlled using the power and control unit with manual settings (12). In the middle of the test specimen a digital thickness gauge (8) with displacer (7) resting on the fabric specimen is placed. The displacer diameter is $2.54 \mathrm{~mm}$, and the displacer area is 5.07 $\mathrm{cm} 2$. The accuracy of thickness measurement is $0.001 \mathrm{~mm}$. The full measurement range of the thickness gauge ranges from 0 to $25.4 \mathrm{~mm}$. The displacer rests on the fabric under which the reference axle of the thickness gauge (5) is affixed to the support of the thickness measurement system (6). The applied digital thickness gauge is also furnished with displacement force setting (11). The whole system is connected to the computer 
(14) through the computer interface with $A / D$ converter (13) and controlled by the serial port.

\section{Results and Discussion}

For each fabric (F1 and F2), results are shown on diagrams Figures 2-3. The measures have been made on 2 samples in each direction in warp and weft. The Microsoft Excel software was used for statistical analysis of data at $p<0.05$ for five measurements.

The known mechanisms of the fabric longitudinal deformation during a tensile test can be described as follows: first, low decrimping of yarns, and fabric structure rearrangement due to internal stresses; these two mechanisms occur under low loads and provide low decrimping of stretched yarns; weave reaction and high de-crimping of the yarn in the direction of the test; and direct yarn strengthening when decrimping is complete. Before analyzing each fabric behavior, it is worth noticing the different initial thickness values, Table 1. These differences were expected because of the difference in fabric weft density. Fabric thickness measurement is highly dependant on the applied tensile force during the measure. Fabric thickness changes while the tensile
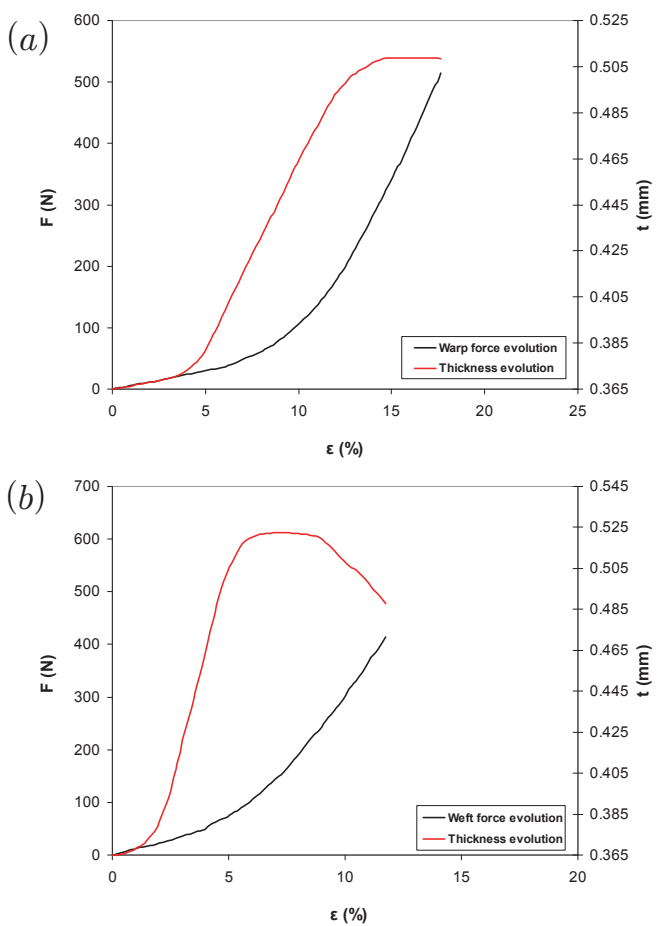

Fig. 2: Diagram of tensile force-relative extension-thickness ( $F-\varepsilon-t)$ for fabric F1: (a) Force acts in the warp direction. (b) Force acts in the weft direction. force stretches the fabric. Thickness - axial force -extension curves in Figures 2 and 3 show typical non-linear relationships for fabric samples if tensile force acts in the weft or warp direction.

As is shown in Table 1, the number of yarns/cm is higher in warp than in weft. The woven fabric F1 has been tested because it is lightweight. Between 0 and $4 \%$ of strain in warp direction, and 0 and $2 \%$ of strain in weft direction, increasing thickness is very small. Between 4 and $12 \%$ of strain thickness is growing up from 0.375 to $0.505 \mathrm{~mm}$ within the warp. From 2\% to $5 \%$ of strain in weft direction, thickness increases very fast from 0.370 to $0.525 \mathrm{~mm}$.

For woven fabric F2, if the force acts in the warp direction in the extension range from $\varepsilon=0 \%$ to $\varepsilon=4 \%$ fabric thickness slightly increases to 0.381 $\mathrm{mm}$. While the values of relative extension rise from $\varepsilon=4 \%$ to $\varepsilon=15 \%$, fabric thickness rapidly grows and reaches $0.511 \mathrm{~mm}$. From 2\% to 6\% of strain in weft direction, thickness increases very fast from 0.379 to $0.529 \mathrm{~mm}$.

Figures $2 \mathrm{~b}$ and $3 \mathrm{~b}$ show that in case if force acts in the weft direction with increasing weft density, the values of tensile forces and associated elongations
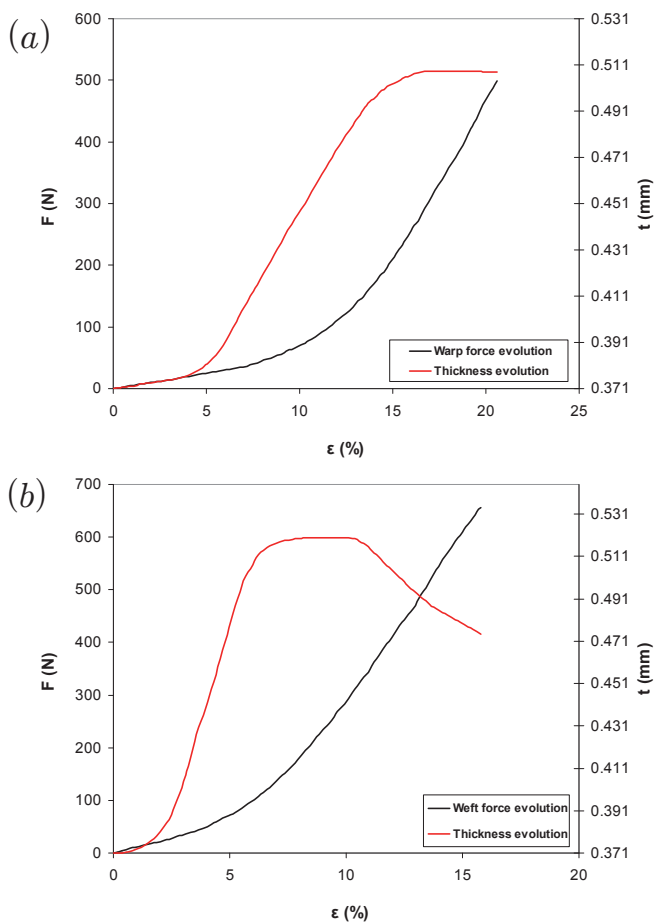

Fig. 3: Diagram of tensile force- relative extension-thickness ( $F-\varepsilon-t)$ for fabric F2: (a) Force acts in the warp direction. (b) Force acts in the weft direction. 
at break of the fabric test specimen increase.

\section{Conclusions}

Measurements of fabric dynamic thickness were performed on a newly constructed measuring apparatus which simultaneously records all necessary values of changing tensile force and associated extension. Fabrics of different weft densities reach approximately the same maximum values of relative fabric thickness with almost equal forces and relative extensions. It follows that weft density does not affect fabric thickness if it is subjected to the action of tensile force in the weft direction. Test results have shown that an increase in axial tensile forces on the fabric causes an increase in fabric thickness for all fabric densities.

\section{References and Notes}

[1] Olofsson B, (1964). A general model of a fabric as a geometric-mechanical structure. Journal of the Textile Institute Transactions, 55, 541-557.

[2] Xiao X et al., (2014). Through-thickness permeability modelling of woven fabric under out-of-plane deformation. Journal of Materials Science, 49, 7563-7574.

[3] Haven G. B., (1933). New Fabric Thickness-Measurer. Textile Research Journal, 3, 229-237.

[4] Schiefer H. F., (1933). The compressometer: An instrument for evaluating the thickness, compressibility and compressional resilience of textiles and similar materials. Textile Research Journal, 10, 505-513.

[5] Majumdar A, Saha S. S., (2008). A novel fabric thickness and compression tester using magnetic inductance principle. Journal of the Textile Institute, 99, 359-362.

[6] Fan J, et al., (2002). A portable tester for nondestructively measuring fabric properties. Textile research Journal, 72, 21 26.

\section{Biographical notes}

Diana Šimić Penava, prof., Ing., Ph.D.: (born in 1970) is a full professor at the Faculty of Civil Engineering, University of Zagreb, Department of Engineering Mechanics, Chair for Mechanics of Materials and Testing of Structures. She graduated from the Faculty of Civil Engineering in 1995 and obtained the Ph.D. degree in 2003 at the same faculty. Her research areas are theoretical and experimental researches on the transfer of load, bearing capacity, stability and usability of laterally supported thin-walled open cross-sectional bearers in the field of thin-walled bearings theory. She also deals with interdisciplinary research into the science of material mechanics. She is an author/co-author of 2 textbooks, 25 publications in journals (2 papers were registered in Current Contents paper, 23 were registered in WoS and SCOPUS), more than 50 publications in conference proceedings in Croatia and abroad.
Željko Penava, prof., Ing., Ph.D.: (born in 1964) is a full professor at the Faculty of Textile Technology, University of Zagreb, Department of Textile Design and Managment. He graduated from the Faculty of Textile Technology in 1993 and obtained the Ph.D. degree in 2004 at the same faculty. His research areas are Textile Mechanical Technology, Textile Mechanics, CAD / CAM in Textiles, Smart Textiles, Construction and Design of the Textiles. He is an author/coauthor of 6 editorial books, 32 publications in journals (6 papers were registered in Current Contents paper, 26 were registered in WoS and SCOPUS), more than 50 publications in conference proceedings in Croatia and abroad. He has been involved in several grant projects and research tasks. Since 2014 he has been member of Croatian Academy of Engineering.

Željko Knezić, doc., Ing., Ph.D.: (born in 1958) is associate professor at the Faculty of Textile Technology, University of Zagreb, Department of Textile Design and Managment. He graduated from the Faculty of Textile Technology in 1983 and obtained the Ph.D. degree in 2012 at the same faculty. His research areas are Textile Mechanical Technology, Textile Mechanics, CAD / CAM in Textiles, Smart Textiles, Construction and Design of the Textiles. He is an author/co-author of 1 chapter in the book, 10 publications in journals (1 paper was registered in Current Contents paper, 9 were registered in WoS and SCOPUS), 29 publications in conference proceedings in Croatia and abroad. 